\title{
Activating the welfare subject: the problem of agency
}

\author{
ABSTRACT \\ While accepting Banton's (2016) view that sociology and social policy are distinct \\ disciplines, this paper argues that times of radical change can profitably bring the two into \\ closer dialogue. Considering an argument from Emirbayer and Mische (1998) that agency \\ becomes especially apparent in unsettled times, it focuses on conceptions of agency at play in \\ the design and implementation of recent UK welfare reforms, and in subsequent legal \\ challenges. Identifying a series of key measures in the Welfare Reform Act of 2012 and the \\ Welfare and Work Act of 2016, this paper examines the challenges that have ensued, and the \\ way that agency is revealed as both a site of disciplinary control and as a focus for \\ contestation, pitting the purposive rationality of welfare reform against the practical reason \\ that emerges from claimant experience.
}

Key words: agency, conditionality, contestation, incentivisation, rationality, welfare

\section{Introduction}

A recent article in this journal (Banton, 2016) argued persuasively that sociology and social policy should be viewed as distinct disciplines, addressing different kinds of problem and seeking different kinds of knowledge. The key to these differences lies in Banton's distinction between theoretical and practical knowledge, and while accepting the validity of his position, there is a sense in which radical change, such as the recent UK welfare reform, can profitably bring the two disciplines into closer dialogue. The focus of the present paper is therefore the welfare programme ushered in from 2010 by the Coalition government, and further advanced by its 2015 Conservative successor. The rhetoric, design, and assumptions associated with these reforms are all of sociological interest, but of particular import is the 
conception of agency in play, both as a site of disciplinary control and as a focus for contestation.

\section{Problematising agency and the welfare subject}

It has been widely observed (Mau, 2003; Duevell and Jordan, 2002; Munch, 2012) that Britain, together with a number of other European countries, has been engaged in a move away from solidaristic models of welfare to individualised responsibility resting on 'activation' of the welfare subject. There has been an associated heightening of requirements placed on claimants, and an expansion of groups deemed capable of and available for work, while Wright (2012) has advanced a corresponding argument that this shift relies upon an inadequate conception of agency. In this context, agency may be construed as a form of purposive rationality, both in terms of the objectives driving the welfare reform, and the disciplinary devices on which they are based.

The purposive rationality manifest in claimant 'activation' has a long history, and is associated by Sayer (2011) with a tendency in modernism to reduce rationality to instrumental reason. He sees the strongest expression of this tendency in mainstream economic theory (cf. Shapiro, 2005), where it features as the pursuit of profit maximisation, through a means-ends approach confined to its own internal logic. The development of the welfare state and its bureaucratic administration may be viewed as part of this configuration (Tweedy and Hunt, 1994), designed to secure social integration under conditions of economic inequality. However, fiscal crisis and an associated pursuit of deficit reduction have brought an increasing emphasis on the disciplinary potential of the welfare system, driven by incentives, conditionality and sanctions. 
Critique of the purposive rationality underpinning such developments has been based on its overextension, its neglect of 'practical reason' rooted in individual experience and contextual sensibility, and the exclusion of broader based systems of value that treat people as ends in themselves, rather than means to other ends (Sayer, 2011:61-2). The ensuing tensions are apparent in most welfare regimes, which are caught between the Marshallian ideal of full inclusion and a more disciplinary focus dedicated to the optimal extraction of labour. In the contemporary drift towards the latter, Wright (2012) argues that attendant policies carry assumptions about motivation, choice and responsibility built on individualised conceptions of culpability and accountability that then legitimise increased conditionality and compulsion.

Driven by a quest for behavioural change, policy has been fashioned around a diminished view of agency that leaves little room for more nuanced understandings of individual subjectivity, self-reflexive thought and action, or the way that agency is differentiated by varied combinations of individual and societal factors. An appreciation of how this diminished conception operates must consider not only underlying assumptions about motivation, behaviour, and feasible outcomes, but also the circumstances in which agency is exercised and that variously shape the claimant experience.

Prominent among these is the institutional setting and the specified requirements and conditions of a claim, to be understood in Wright's terms as 'context creation'. Giddens (1979:50) has noted a failure to relate action theories to institutional transformation, such that institutions appear as a consensual backdrop against which action is engaged, without a related focus on power relations or conflict in society. In the case of welfare, the regulated interactions required by the system and their attendant differentials of power and knowledge constitute the circumstances within which welfare subjects exercise agency. This context operates in part through a process of classification that determines what can be required of 
which categories of claimant, as well as the claimant's ability to negotiate and possibly contest the classifying process.

More detailed regulations govern implementation, but alongside these purposive constraints lie life-world factors, captured by Emirbayer and Mische's (1998:963) understanding of agency as 'a temporally embedded process of social engagement, informed by the past but oriented to the future'. We can therefore infer that actors carry into the present not only future oriented projects, but a variety of relations and obligations already established. Emirbayer and Mische characterise the outcome as a web of cognitive, corporeal and affective schema that shapes action - and this configuration is an orienting theme of the present paper.

A point of particular interest is their argument that the locus of agency lies in the range of possible responses to problematic situations. They therefore point to key moments of transformation and/or crisis, and bring a political significance to bear by noting that day to day interactions occur within 'master frames' that are part of the broader political culture. In so doing, they not only endorse a view of structure and agency as mutually constitutive (see Giddens, 1979), but suggest that agency becomes especially apparent in unsettled times, such that pivotal moments may emerge in situations of political realignment.

Wright's (2012) approach to recent UK welfare reform offers a vehicle for taking forward this argument through an analysis of the narrowly framed conceptions of agency in operation at policy level. She notes a tendency in welfare policy to see intention and choice as a form of calculative self-interest at the level of the individual, to the neglect of personal constraint, social context and social bonds. Furthermore, since related policy measures carry moral messages about behaviour and motivations (Author A, 2016) she points to an additional dimension of agency that operates through the production of meaning at policy level itself, again bridging the structure-agency divide. Thus, policy makers are not to be construed as 
impartial rational actors, but as active agents who advance policy measures imbued with moral messages, and implemented by profit-based delivery agents with their own interests at stake. Hence, Wright calls for research that captures the 'more nuanced aspects of agency', and here we might look to the crisis points generated within this system.

Distinguishing between action and agency, Reed and Weinman (2019:10) argue that while action entails an engagement with future projects, agency implies a high probability of bringing such projects to fulfilment. Success, they suggest, is enhanced by the ability to enlist others as one's agents, thus constructing an 'agency chain' (p14). However, in the case of welfare reform, such 'fulfilment' requires co-option of the welfare subject, whose own agency - shaped and constrained by their principles, interests, capacities and obligations comes into play. The present paper therefore examines how the objectives, incentives and sanctions driving welfare policy collide with the complexities of lived experience, as revealed below in a series of legal test-cases. We show how such challenges variously provide a forum for the elaboration of contested conceptions of agency, pitting the purposive rationality of instrumental reason against the lived experience of claimants, whose agency may be better understood in terms of practical reason.

\section{Research focus and methods}

The central purpose of this paper is an exploration of these contrasting conceptions of agency through interrogation of a set of legal judgments that place agency at issue. We begin with a brief outline of the rationale driving welfare reform in Britain from 2010 onwards, and the key policy measures at stake. This account is gleaned from a thematic reading of position papers and related legislation outlining the orientation, aims and purpose of policy, and the measures they have generated. More crucially, the paper examines a series of legal challenges to the measures identified - test cases that are widely circulated within the practitioner 
community - and the heart of the argument is derived from analysis of the ensuing judgments. The focus here is less on the detail of legal reasoning than on what the cases reveal about policy assumptions concerning agency, their implementation in practice, and attendant problems for claimants.

In identifying relevant cases one determining factor was that they should span the range of targeted reform measures detailed below. In relation to these measures, each case identifies a distinct policy problem, addresses a key point of law, and stands as a referent for policy adjustment and/or future litigation. They were not therefore 'sampled' from a general population of cases but are rather test cases whose outcome will shape the treatment of a host of similarly placed claimants. Such cases are part of a process that emerges from the actions of advocates and litigants who identify policy or practice issues ripe for legal challenge. For markers of this test-case status, we may note: all but one of the cases involved civil society advocacy groups in bringing the case to court and/or acting as interveners; most of the cases were appealed to a higher level court (Upper Tribunal, Court of Appeal or Supreme Court); and almost all required a significant adjustment of policy or practice. The exception to the latter point is the lone parent benefit cap, which has nevertheless exposed disagreement within the judiciary.

Given this test case rationale, each challenge provides an opportunity to examine those aspects of agency called into play by the implementation of specific policy measures, and to explore the situated agency apparent in the claimant experience. This approach of course confines the paper to a consideration of the individual agency at issue in each case, though this is not to deny that other forms of resistance could engage collective agency. However, that is not the focus of the present argument, and within this constraint, close interrogation of the test-case judgments uses agency as a lens through which to view the critical points at 
issue in policy implementation. This sets the analytical frame, and means that agency must be read into the dynamic of legal dispute. The analysis below therefore examines the purposive rationality of behavioural change against a more sociological understanding of agency that better engages the claimant experience

\section{Policy rationale and the question of value(s)}

We see from the argument above that institutions may be implicated in the shaping of social norms, and a welfare system is built around not only fiscal but moral assumptions, which in turn have a role in steering popular opinion (Mau, 2003; Rodger, 2003; Munch, 2012). Policy is thus, at least in part, a normative endeavour, and a disciplinary welfare regime that implies the need for coercion will generate a corresponding stigma for the welfare subject, negative perceptions of their agency, and attendant erosion of their moral standing in society. This process can be traced through the programme of welfare reform that has emerged in Britain over the last decade, and though these reforms continue trends already apparent (Harris, 2008), they represent a qualitative shift in both reach and severity.

Early papers from the Centre for Social Justice ${ }^{1}(2006$; 2007) foregrounded the need to 'get tough' on fraudulent welfare claims, and propounded a view that weak expectations had made it possible to choose a life on benefits. The proposed solution was a system designed to produce 'positive behavioural effects', so among the recommendations was that unemployed claimants should be actively seeking or preparing for work on a full-time basis, and that this should extend to disabled claimants and to lone parents. Such a system would be accompanied by robust application of financial sanctions for failure to comply, and intense enforcement through competition between providers rewarded for positive outcomes. These arguments reappeared in a Conservative Party Green Paper (2008) that also advocates a 'culture of responsibility' to counter the 'culture of dependency', and became concrete 
proposals under the incoming Coalition government (Department of Work and Pensions (DWP), 2010a; 2010b). Recurrent policy priorities are financial savings, fairness to hardworking taxpayers, increased welfare conditionality, and incentivising work (DWP, 2010a; Kennedy, 2015), all embraced by the Welfare Reform Act (2012) and further advanced by the Welfare Reform and Work Act (2016)

The most ambitious change has been removal of the distinction between working and workless claimants through a unified system of Universal Credit ${ }^{2}$ (DWP, 2010b), though full implementation has been delayed in the face of administrative problems, claimant suffering, and poor labour market outcomes (National Audit Office, 2018). Meanwhile, however, a series of measures have been established under the pre-existing system, and carried over into Universal Credit, that make policy questionable even within its own narrow behavioural terms, all having issues of agency at their heart.

- The 2012 Act heightened claimant conditions and financial sanctions for failure to comply, intended 'to provide a greater incentive for people to meet their responsibilities' (DWP, 2010a:4). The system has operated with three levels of severity by type and frequency of offence, and with removal of benefit from a minimum of four weeks to a maximum of three years (previously from one to 26 weeks) (Work and Pensions Committee, 2018).

- Tighter Work Capability Assessments (WCA) and heightened sanctions have affected Employment Support Allowance (ESA - previously Invalidity Benefit) for those classed as having a limited capability for work (the Work Related Activity Group - WRAG), prompting concern over faulty decisions and inappropriate conditions (Kennedy et al, 2017b). 
- The age of the youngest child at which lone parents are moved onto Jobseekers

Allowance and thereby full conditionality has been lowered in stages from 14 years in 2007 (Harris, 2008) to five in 2012, and three in 2016 - intended 'to enable lone parents to take financial responsibility for themselves and their children' (Work and Pensions Committee, 2018:22-3)

- The 2012 Act introduced a cap on the total amount a household can receive in benefits, set at $£ 26,000$ per year ${ }^{3}$ for families regardless of size, and lowered to $£ 23,000$ in London and $£ 20,000$ elsewhere by the 2016 Act. The stated aim was to encourage responsible life choices and increase incentives to work (Kennedy et al, 2016b).

- A further measure in the 2016 Act restricted Child Tax Credit (CTC) payments per child to two children, with a potential loss of $£ 2780$ per year, ${ }^{4}$ such that people on means-tested benefits 'should face the same financial choices about having children as those supporting themselves solely through work' (Kennedy et al, 2017a). Available exemptions have proved contentious.

The fertile ground for this 'activation' paradigm is apparent in Skeggs (2014:1) account of a dominant logic in which 'the market has become God'. She argues that monetization and commodification have reduced the person to an object of calculation and domination that constrains conceptions of both who has value and what is valued. As Skeggs makes clear, there is a gendered dimension to these issues when caring work is overlooked both as an economic contribution and an obligation of love and duty. We also see below how limited conceptions of who and what has value can squeeze out individual hopes, ambitions and principles that do not readily conform, and how physical and mental capability become subject to a crude classification of labouring capacity. 
Like Skeggs, Sayer (2011) also notes the limiting influence of economistic orientations based on profit maximisation, which renders an impoverished and alienated approach to understanding social life. He therefore makes a case for the incorporation of values and of 'what matters to people' into social scientific reasoning, based on people's own experiences and priorities in a manner attuned to the conditions required for human flourishing. Such an approach he argues is not based on abstract moral principle, but rather takes seriously people's own personal life plans, their capacities and vulnerabilities, and their care and concern for others. Such an approach incorporates people's own normativity and selfunderstanding into an evaluation of their actions and their experience at the hands of institutions, and we might expect this form of reasoning to feature in the functioning and evaluation of a welfare system.

These arguments are explored below in relation to a series of test-cases that have challenged each of the targeted measures of welfare reform listed above, and the following discussion is grouped according to key policy issues. The cases in different ways reveal the impoverished conception of agency at play in the rationale and implementation of policy, and what happens when this is exposed to contrasting conceptions of agency rooted in claimant experience.

\section{Conditionality and sanctions}

\section{Context creation}

One early case (Reilly and Wilson v Secretary of State for Work and Pensions (SSWP) [2012] EWHC 2292) concerns two claimants sanctioned under programmes within the Employment Skills and Enterprise Scheme. The design and implementation of these programmes impose work related requirements on claimants as a means of imbuing behavioural change in an instance of 'context creation' (Wright, 2012). The challenge raises 
questions about informed participation, claimant knowledge and understanding, and hence the capacity to act, while also showing how the schemes override claimants' own selfassessment of their position and their hopes for the future.

The 2011 Regulations governing the programmes were challenged on four grounds - (1) failure to provide a full description of the schemes; (2) absence of a published policy supplying these details; (3) failure to provide written notice of the consequences of nonparticipation; and (4) forced or compulsory labour. The case succeeded on the third ground in the High Court, and the first and third ground in the Court of Appeal (Reilly and Wilson v SSWP [2013] EWCA Civ 66). The Supreme Court (Reilly and Wilson v SSWP [2013] UKSC 68) agreed, and noted that the person affected by a policy must be in a position to challenge a decision by 'informed and meaningful representations' (UKSC, para 65), and also to make an informed decision about taking part (UKSC, para 67). Crucially, Reilly received no written notice and had been wrongly instructed that participation in the sector-based work academy was compulsory, while neither claimant had received 'adequate accurate information about the schemes in relation to themselves' (UKSC, para 76) before being told that their participation was required. Translated into sociological language, the failure to adequately inform amounted to an impediment to agency, and underlines the power of ‘undisputed practices' (Giddens, 1979:89) in shaping the claimant experience.

However, it is also apparent from detail in the EWHC judgment (para 186) that in resisting the schemes both claimants displayed considerable reflexive agency, as well as a commitment to work. Wilson had objections in principle to working for free, and viewed the requirements as: 'pointless work that has not been arranged by looking at my own needs' (para 112) that actually hampered his jobsearch. Reilly hoped for a career in the museum sector and was working there voluntarily to acquire sufficient experience. As the EWHC 
judge remarked, the scheme 'impeded her voluntary efforts to maintain and advance her primary career ambition... and did not offer any worthwhile experience on an alternative career path', while for Wilson 'there is no suggestion that he would not take suitable employment if he could find it' (para 126)

The experience of both claimants raises questions about knowledge, understanding, choice and reflexivity, and goes some way towards undermining the rationale of both programmes and their related sanctions regime. A scheme dedicated to behavioural change had insufficiently informed claimants, frustrated their reflexive agency, and impugned their moral standing. However, the fuller elaboration of requirements could well have perverse effects, facilitating a form of 'calculative agency' through increased administrative capacity for monitoring and enforcement (Adkins, 2017).

\section{Claimant context}

The sanctions regime has attracted more general criticism for the high success rate on appeal (Oakley, 2014; CPAG, 2018), poor appreciation of claimant circumstances, and inadequate application of 'easements' - adjustments that take mitigating factors into account. A case in the Upper Tribunal (UT) (RR v SSWP (UC) [2017] UKUT 459 (AAC)) focussed less on the rules themselves than on their application and interpretation, and the ensuing judgment illustrates a range of related factors bearing on conceptions of agency

RR was a Universal Credit claimant given two 28 day sanctions for failure to comply with her Claimant Commitment - a requirement for all applicants. The UT judge observed that this document began with the 'positively Stakhanovite statement' that 'I'll do everything I can to get paid work', including obeying instructions from the Work Programme provider and the obligations contained in her Claimant Commitment. The latter requires 35 hours per week 
spent seeking and preparing for work, and daily access to a Universal Jobsearch account, cautioning that failure to comply 'without good reason' would mean loss of $£ 10.40$ per day for up to three years.

Having claimed Universal Credit for one year, RR complained about a newly allocated work coach, and received an apology from the Job Centre. However, this work coach had imposed two sanctions for failure to engage in 35 hours per week job-search, and after an unsuccessful internal review (Mandatory Reconsideration) the claimant appealed, again without success, to the First tier Tribunal (FtT). She explained that she had logged onto the Universal Jobsearch system as required but neglected to update her record due to distractions from a family crisis she was reluctant to disclose to the new work coach. She felt this omission should have been noticed as 'an oddity' given her record of compliance. On further appeal, the Upper Tribunal (UT) found that the FtT judge had erred in treating the 35 hour jobsearch requirement as immutable. Deductions could be allowed for temporary circumstances, which include a domestic emergency, and the latter could reasonably embrace the claimant's divorce hearing due some months later, with its attendant stresses (para 31). The UT therefore found for the claimant.

This history highlights the complexity of individual agency in such cases - and while the regulations do in fact allow scope for dealing with temporarily disruptive events, their application and interpretation rested on the unsatisfactory work coach and an error on the part of the FtT judge. The moral standing of the claimant was again at issue in relation to motivation and good faith in meeting the conditions of her claim. More significantly, the history raises the question of reasonable expectation when individual agency is impaired by a domestic crisis and thus closely tied to relations with others - an instance of Wright's interconnected agency. 


\section{Capability and caring}

Classifying embodied agency

Human agency is also necessarily embodied, and this recognition has particular significance for ESA claimants, in relation both to the decision-making process, and the significance of its outcomes. The requirements imposed on claimants are determined by a threefold classification - full conditionality, work related activity (the WRAG), and no conditionality (the Support Group) - resting on judgements of capacity and therefore agency. However, the WCA itself raises questions about capacity and agency in terms of the ability to navigate assessment, especially for those experiencing a mental health condition. Ruling on an earlier UT judgment, the Court of Appeal (MM and DM v SSWP [2013] EWCA Civ 1565) found mental health patients were placed at a substantial disadvantage, in breach of a duty under the Equality Act 2010 to make reasonable adjustments to secure as full as possible entry into everyday life (and hence full agency).

Both the outcome in terms of benefit entitlement, and the experience of the assessment itself were held to be implicated (para 73-7). Decisions about capacity to work were undermined by the failure to secure full understanding and engagement from those undergoing assessment, compounded by lack of expertise among assessors, and an intimidating determination process, which could generate false or inadequate judgements (para 31).

Critical commentaries (Kennedy et al, 2017b; Murphy and Keen, 2016) have noted that the WCA is too simplistic, overstates capacity, deals badly with fluctuating conditions, and is difficult for claimants to navigate - especially since $50 \%$ have mental and behavioural disorders. However, many feel unable to contemplate an appeal (Rethink Mental Illness, 2017), and in 2013 a prior requirement of in-house Mandatory Reconsideration posed an 
additional barrier, prompting further challenge. A Mandatory Reconsideration request was required within one month of a decision, or under 'special circumstances' up to 13 months afterwards. Refusal of an extension in effect established the DWP as gatekeeper to the independent appeal process, raising questions of fairness, access to justice, and the power to decide, all of which rebound on agency.

A decision in the case of two refused ESA claimants (CJ and SG v SSWP [2017] UKUT 0324 (AAC)) reasserted appeal rights for all DWP benefits, since the judge saw a high risk that merited claimants would miss the time limit, and thus lose benefits to which they were entitled. Noting that 'many claimants will be vulnerable for reasons including issues relating to their mental health or learning disabilities' (para 83), the judge stressed 'the ordinary need to have regard to context in the application of any legal rule' (para 61) and to 'the realities relating to persons claiming benefits' (para 86).

This judgment in effect underlines the importance of contextual agency, but despite concern about the assessment process those appealing a negative decision for the WRAG are treated as Jobseekers with attendant requirements until the decision is overturned. Hence, a questionable assessment of capability exposes claimants to the behavioural requirements of full conditionality, with financial penalties, bodily suffering, and impugned moral standing should they fall short. Reported effects include a worsening of conditions, anxiety and financial hardship, and individual trauma, further undermining agency and work prospects (Kennedy et al, 2016a).

\section{Embodiment and Interconnected agency}

Mis-directed 'incentives' to work and related questions of agency have also arisen from the benefit cap, which allows exemptions for households in receipt of some disability benefits - 
Attendance Allowance, Disability Living Allowance, and Support Group ESA. A case arose concerning the non-exemption for recipients of Carers Allowance - a benefit for people providing 35 hours of care per week, whether or not in co-residence. Some co-resident carers fall under the household exemption for Disability Living Allowance, but the official definition of a household is confined to partners and dependent children, so does not cover non-spousal or non-resident adult carers. The case at issue (Hurley and Ors v SSWP [2015] EWHC 3382 (Admin)) challenged a failure to fully accommodate constraints entailed in intimate obligations of care for others - again highlighting the interconnected rather than purely autonomous nature of agency.

The purpose of the cap, as outlined by the relevant minister, is 'all about influencing behaviour' (para 18), and a DWP official explained that it was 'designed to achieve long term behavioural effects by changing attitudes to welfare and work'. Carers subject to the cap should therefore face the same choices as others - to take up work or adjust their budget (para 25). However, the claimants at issue were involved in complex relations of mutual support that constrain their options. One was a lone parent of four children who also cares for her grandmother, and was evicted as a result of the cap; the other was a grandson who himself suffers from mental health problems and dyslexia, but provides non-residential support for his grandmother. In both instances, the 'choices' available to the carers - taking up employment and/or moving to cheaper accommodation ${ }^{5}$, would disrupt a pattern of care and mutual support at considerable cost to the state (para 35). The judge also noted: 'to describe a household where care was being provided for at least 35 hours a week as 'workless' was somewhat offensive' (para 28).

The non-exemption of carers allowance from the cap was thus deemed indirect discrimination against disabled people, and in delivering this decision the judge urged reconsideration of the 
policy, given 'the hardship it can and does produce and the lack of real benefit to the State' (para 75). More significantly, the claimants' agency is shown to be rooted in a pattern of mutual support that official definitions of a 'household' and ill-informed conceptions of autonomous behavioural motivation fail to recognise or accommodate.

\section{Lone parents and the benefit cap}

Identity, agency and inter-subjectivity

The benefit cap also raises problems for lone parents that demonstrate other aspects of the interconnected nature of agency, and its relation to identity and inter-subjectivity. One such case (JS and Ors v SSWP [2013] EWHC 3350) followed initial implementation of the cap at $£ 26,000$. The stated aims are to produce a reduction in welfare spending, a shift in welfare culture by incentivising work, and fairness to working taxpayers (para 1), but among the benefits included in the calculation are those paid on behalf of children. A challenge was brought on behalf of three single parents and their youngest child (all aged below four), based on various forms of discrimination under the European Convention on Human Rights.

However, the case came to turn on gender discrimination, together with the unreasonableness of the measure in common law. It was argued that a large majority of those affected were female lone parents, that under the 2012 Act lone parents with a child under five were not required to work (para 99), and that working households were anyway better off before the introduction of the cap (para 89).

Agency entered the picture through the argument that 'it is quite unrealistic to believe that these claimants can work' (para 82), in view both of the difficulties of childcare arrangements and the lack of available jobs. Furthermore, the alternative response of moving to cheaper accommodation was problematic in relation to children's educational stability, available 
support networks, and in two cases their strong cultural/religious character. The interconnected nature of these constraints is heightened by the fact that two of the women were fleeing domestic violence and thus had limited housing options - all indicating that mothers of young children are not independent agents in a position to respond to simple financial incentivisation.

The same arguments were rehearsed on appeal (SG and Ors v SSWP [2014] EWCA Civ 156) but the Secretary of State justified the policy as advancing change in the welfare culture (para 44), arguing 'If child-related benefits had been excluded from the cap its discriminatory effect on women generally would have been reduced or eliminated altogether. But the scheme would have been seriously emasculated' (para 56). The appeal failed, and in effect, lone parents were to be incentivised by removing needs-based benefits from their children, but the identification of women's interests with those of their children, and the impact on their agency became central on appeal to the UKSC (SG and Ors v SSWP [2015] UKSC 16).

A majority of the judges (three of five) argued that treatment of the child does not depend on the sex of the parent, and thus had no bearing on the claim of gender discrimination. However, a dissenting minority of two supported the appeal and as Lady Hale argued, the government must not simply justify the cap, but explain why they adopted a scheme that has disproportionately adverse effects upon women (para 188). While disability-related exemptions mean the cap does not apply to those least able to work, the same logic had not been extended to lone parents with a child under five (para 200). They were also not required to work but lost benefits otherwise available to cover their own and their child's needs (para 209). Lord Kerr goes further to question whether the interests of lone mothers can be separated from those of their children: 'A mother's personality, the essence of her parenthood, is defined not simply by her gender but by her role and responsibility as carer of 
her children' (para 264). The compulsion to work or the removal of benefit both place this responsibility at issue.

The view that the cap is discriminatory therefore engages women's agency through the argument that their employment options are constrained by caring responsibilities, that a reduction in the benefit paid on behalf of children is being used to incentivise lone mothers into work, and that in the absence of employment these women are dependent on state benefits to fulfil a caring role that is part of their identity. Their agency is thus construed as a feature of the inter-subjective relationship with their child(ren).

\section{Differing degrees of agency}

The majority UKSC judgment above dismissed the appeal, seeing the disparity of impact between men and women as having an objective and reasonable justification (para 96). A further case (DA and Ors v SSWP [2017] EWHC 1446 (Admin)) looked to the particular position of lone parents (regardless of gender) with a child under two, in another instance of inter-connected agency. By this time the cap had been lowered and lone parents with a child aged three or over had been made subject to full conditionality. The point at issue was 'the difficulty and sometimes impossibility of lone parents with a child under two of being able to work' (para 16), as recognised in their exemption from work-seeking requirements. The parents concerned 'are not workshy but find it, because of the care difficulties, impossible to comply with the work requirement.' (para 43)

The argument thus turned on their restricted agency. The claimants were not lone parents by choice (paras 30), and incentivising them to work 'had no real traction in circumstances where there was no realistic prospect of working.' (para 86). However, in the subsequent appeal (DA and Ors v SSWP [2018] EWCA Civ 504) evidence had to show the parental 
situation to be 'materially different' from other claimants (para 92), and the majority opinion relied on a debateable interpretation of relevant statistics (para 109). 16\% of lone parents with a child under two who had been capped had moved into employment, and this was deemed insufficiently different from the $30 \%$ of those with a child under five who had done so. The former group did not therefore constitute a distinctive 'other status'.

Against this view, a dissenting judge looked to expert commentary and general knowledge of the greater problems and costs involved in child care for very young children (para 156), especially given a shortage of suitable jobs, and the uncertainty involved in flexible working and zero hours contracts (para 170-1). However, the EWHC decision was overruled - in effect, constraints on the agency of lone parents with a child under two were not deemed sufficiently different from other lone parents to amount to a case of discrimination, a decision upheld by five to two in the Supreme Court.

\section{'Choice' and the two-child limit}

This final case is a challenge to the two-child limit on CTC, applicable to new claims from February 2019. CTC is a means-tested benefit for households both in and out of work, a guaranteed minimum now to be removed in a measure that claims to enhance the life chances of children through responsible decision making by parents. The stated aims revolve around agency in terms of parental decisions about family size, but despite exemptions do not fully accommodate unforeseen circumstances.

Exemptions covered by the Regulations include multiple births, adoption where a child would otherwise be in care, non-parental care, and non-consensual conception (rape). All were to apply only to the third child, and hence, the only routes to CTC for a third child would be multiple birth or rape - the latter stigmatising the child concerned. A further 
requirement that in such cases the mother should not be living with the perpetrator in practice removes support at a critical time and undermines the woman's capacity to leave ${ }^{6}$. A case was brought on behalf of four adults (SC and Ors v SSWP [2018] EWHC 864 (Admin)), each with a third or subsequent child for whom CTC was not payable - variously resulting from abuse, a failure of the birth control pill, medication as an impediment to birth control, and care of a grandson.

The policy aim foregrounds reflexive agency in urging parents to 'think carefully about whether they can afford to support additional children' (para 30). However, the challenge points to a flawed notion of 'choice' in that 'conception and birth cannot be neatly categorised as voluntary or involuntary' (para 47). Though gendered constraints are again apparent, there was no clearly defined group on which to hang a discrimination charge, and the aims of the policy were deemed legitimate and lawful (para 148). This left only one outstanding feature of the challenge - the exception for cases of non-parental care. The judge found that confining this exception to children born before non-parental care was engaged was irrational in discouraging a family from assuming a responsiblity that would otherwise fall to the local authority.

Despite having little further legal purchase, the case reveals the flawed assumptions behind the policy and its failure to engage with life as it is lived by many of those affected. Indeed, a House of Lords (2017) committee found that official responses to criticism amounted to little more than stock phrases, doubted that the measure could ever be made to work, and felt it risked punishing families for circumstances beyond their control.

Though questions may be raised about the representative nature of these cases, something can be said of their general applicability. The Reilly and Wilson case determined the treatment of an estimated 3789-4305 related appeals ${ }^{7}$; the judgment in $R R v S S W P$ was explicitly issued as 
guidance for other such cases (para 2); carers allowance has now been exempted from the benefit cap; the WCA has been found to disadvantage mental health patients - half of its clientele (Kennedy et al, 2017b:3); the right of appeal for all DWP benefits has been reaffirmed; and the two child limit has been amended to exempt non-parental care. While lone parents have not been similarly successful, they do account for $85 \%$ of households subject to the benefit cap (Guardian, 2019), and their treatment has provoked disagreement within the judiciary and in Parliament.

\section{Purposive rationality and practical reason}

The cases above each address a particular feature of Britain's recent welfare reform, and each is bound up with policy objectives aimed at behavioural change. They all open up questions concerning conceptions of agency that both invite and inform sociological thinking on this topic. The policies entailed address agency through financial incentives, behavioural requirements and associated sanctions, but with scant recognition of the context in which agency is exercised, and little accommodation of more complex features of capacity and interconnectivity.

It was noted above that the measures documented can be construed as a form of purposive rationality, both with respect to the objective of behavioural change and the means adopted to achieve this. However, it has also been argued that they are based on a pared down understanding of agency that leaves out of account what Sayer terms practical reason, as revealed by a more situated appreciation of the claimant context. The cases explored each exemplify different aspects of the tension between these contrasting understandings of agency. Each also demonstrates the narrow institutional framing of who has value and what is valued, whether in relation to individual hopes and plans, accommodation of varied and 
variable capabilities, patterns of care and concern for others, or the whole complex fabric of claimants' lives.

Incentives, caps and coercion thus reflect the institutional conception of agency as it appears in the welfare context. This, Giddens would argue, amounts to more than a consensual backdrop but conveys a distinctive moral message fashioned by active policy agents initiating what Reed and Weinman would term an 'agency chain'. However, given the central objective of behavioural change, an understanding of how policy is experienced by claimants is crucial to its efficacy and its legitimacy, both in terms of the regulatory framework in operation and its mesh with the complexities of every-day life. Each of the measures sketched out in the present paper thus constitutes a pivotal moment in the unfolding of a distinctive welfare culture, as the 'master frames' noted by Emirbayer and Mische (1998) encounter the constraints of lived experience.

Interrogation of the legal challenges that identify and isolate these moments has served here to demonstrate complexities of agency that go far beyond the policy rationale. The cases considered respectively engage context creation in terms of governing regulations and requirements; complexities of claimant circumstance that require nuanced interpretation; capacity and agency in the classification of claimants, their ability to negotiate the system, and the determination of (in)appropriate requirements; embodied agency and inter-connected agency in relation to varied obligations of care; inter-subjectivity that binds together the interests of mother and child; and the illusion of choice in circumstances that may defy individual control. All take a distant second place in a drive for optimal extraction of labouring capacity and defence of the hardworking taxpayer.

The sociological interest of the cases goes further than an abstract opposition between conceptions of agency based respectively on purposive rationality and practical reason. 
Critical commentary on the impact of welfare reform has noted the disproportionate impact on women and on people with disabilities (Butterworth and Burton, 2013), and several of the cases above show why. They reveal the ways that agency may be internally differentiated by limitations rooted in gendered responsibilities, and by failures to accommodate variable degrees of physical and mental capacity. They also show that these constraints could be ameliorated by appropriate policy intervention. There is therefore a strong argument not only for translating abstract conceptions of agency into embodied and situated human existence, but also for viewing agency in the context of institutional enabling or constraint, making policy part of the picture.

Against a background of political realignment and a reconfiguration of the welfare system, the cases point in different ways to inadequate conceptions of agency at play in the design and/or implementation of policy. They provide concrete examples of the questionable nature

of policy assumptions within an actively constructed agenda that seeks to impose behavioural change to the neglect of situational, relational and embodied context. Yet these assumptions are crucial to the moral message of welfare reform, in that agency carries with it an associated conferment of responsibility, and thus has an impact on moral standing and reasonable expectation. Agency, however, emerges as the fulcrum for the crises produced when political master frames clash with the reality of claimant experience, and hence provides a focal point for contestation - albeit within the narrow constraints of legal purchase.

\section{Conclusion}

The cases considered all expose anomalies in the formulation and implementation of policy, and most yield successes that have forced procedural or policy refinement, but the broader framework of reform remains largely intact. Amending the flaws of policy design and implementation revealed by the cases considered cannot of course supplant the wider moral 
assumptions and social steering that the welfare reforms embrace, though they go some way towards undermining them. A more fundamental challenge would need to displace the moral messages and underpinning objectives that lie behind measures advanced by the welfare reform. Yet viewed through a sociological lens, the cases reveal ill-formed policy assumptions, limited understanding of claimant circumstances, and questionable attributions of individual responsibility that rebound on the moral standing of claimants, while also furnishing real life instances of the complexity of human agency.

This paper began with a reference to Banton's argument that sociology and social policy are distinct disciplines that rest on different kinds of knowledge - the theoretical and the practical. However, the argument presented above suggests a more nuanced approach. The distinctions Banton makes may be better viewed as extreme ends of a continuum that includes a productive area of overlap across the two disciplines, rather than a clear boundary between them. In the present study, one promising area of commonality lies in the notion of practical reason, which engages both a distinctive conception of agency and a possible focus for policy analysis, and here Banton's two types of knowledge potentially come together. Though policy expertise is best equipped to analyse the technical detail of programme formulation and implementation, and sociological expertise finds its strength in the theoretical and conceptual work of interrogating social actions, social relations and social structures, policy measures nevertheless form part of the substance of social life. Conversely, the cases above show how a sociological understanding of agency can provide a valuable tool for analysing the design and implementation of policy measures, the crisis points that they engender, and their legitimacy in terms of the lived experience of claimants they are meant to serve. 


\section{Endnotes}

\footnotetext{
${ }^{1}$ A think-tank allied to the Conservative Party, in which Iain Duncan Smith (later the Secretary of State for Work and Pensions) was active.

${ }^{2}$ Combining six working age benefits.

${ }^{3}$ Equivalent to net average earnings and excluding benefits available to the working population.

${ }^{4}$ Effective for new claims from April 2017.

${ }^{5}$ Likely to be in a different (cheaper) area.

${ }^{6}$ http://www.cpag.org.uk/sites/default/files/Two\%20child\%20limit\%20consultation_CPAG\%

20response.pdf
}

${ }^{7}$ https://www.whatdotheyknow.com/request/494836/response/1201245/attach/2/Fol\%202998\%20IR\%20414 \%20Reply.pdf?cookie passthrough=1

\section{References}

Author A - anonymised

Adkins L (2017) Disobedient workers, the law and the making of unemployment markets. Sociology 51(2):290-305.

Banton M (2016) Reflections on the relation between sociology and social policy. Sociology 50(5):993-1001.

Butterworth J and Burton J (2013) Equality, human rights and the public service spending cuts. The Equal Rights Review 11:26-45

Centre for Social Justice (2006) Breakdown Britain. London:CSJ.

Centre for Social Justice (2007) Breakthrough Britain. London:CSJ.

Conservative Party (2008) Responsibility Agenda, Work for Welfare. Policy Green Paper 3. 
CPAG (2018) Submission to the Work and Pensions Sanctions Inquiry. London: CPAG.

Duevell F and Jordon B (2002) Immigration, asylum and welfare: the European context.

Critical Social Policy 22(3):498-517.

DWP (2010a) $21^{\text {st }}$ Century Welfare. Cm 7971.

DWP (2010b) Universal Credit: Welfare that Works. Cm 7957.

Emirbayer M and Mische A (1998) What is agency? American Journal of Sociology 103(4):962-1023.

Guardian (2019) Benefit cap. $4^{\text {th }}$ January

Giddens A (1979) Central Problems in Social Theory. London: Macmillan.

Harris N (2008) From unemployment to active jobseeking. A European Work-First Welfare

State. Stendahl S, Erhag T, and Devetzi S (eds.) Gothenburg: Centre for European Research, 49-77.

House of Lords Secondary Legislation Scrutiny Committee (2017) HL Paper 148.

Kennedy S (2015) Welfare Reform and Work Bill. CBP 079252.

Kennedy S, Murphy C, and Wilson W (2016a) Welfare Reform and Disabled People. CBP 7571.

Kennedy S, Wilson W, Apostolova A, and Keen R (2016b) The Benefit Cap. CBP 06294.

Kennedy S, Bate A, and Keen R (2017a) The two child limit. CBP 7935

Kennedy S, Keen R, and Mackley A (2017b) Work Capability Assessment. CDP-2017-0254.

Mau S (2003) The Moral Economy of Welfare States. London: Routledge.

Munch R (2012) Inclusion and Exclusion in the Liberal Competition State. Abingdon:

Routledge.

Murphy C and Keen R (2016) Abolition of the ESA WRAC. CBP 7649.

National Audit Office (2018) Rolling Out Universal Credit. HC 1123. 
Oakley, M. (2014) Independent Review of the Operation of the Jobseekers Allowance

Sanctions. London: OGL.

Reed I A and Weinman M (2019) Agency, power, modernity: a manifesto for social theory.

European Journal of Culture and Political Sociology 6(1):6-50

Rethink Mental Illness (2017) It's Broken Her. London: Rethink Mental Illness.

Rodger J (2003) Social solidarity, welfare and post-emotionalism. Journal of Social Policy 32(3):403-21.

Sayer A (2011) Why Things Matter to People. Cambridge: Cambridge University Press

Shapiro S (2005) Agency theory. Annual Review of Sociology 31:263-84.

Skeggs B (2014) Values beyond value. British Journal of Sociology 65(1):1-20.

Tweedy J and Hunt A (1994) The future of the welfare state. Journal of Law and Society 21(3):288-316)

Work and Pensions Committee (2018) Benefit Sanctions. HC 955.

Wright S (2012) Welfare-to-work, agency and personal responsibility. Journal of Social Policy 41(2):309-28.

\section{Cases}

Reilly and Wilson v SSWP [2012] EWHC 2292

Reilly and Wilson v SSWP [2013] EWCA Civ 66

Reilly and Wilson v SSWP [2013] UKSC 68

RR v SSWP (UC) [2017] UKUT 459 (AAC)

MM and DM v SSWP [2013] EWCA Civ 1565

CJ and SG v SSWP [2017] UKUT 0324 (AAC)

Hurley and Ors v SSWP [2015] EWHC 3382 (Admin)

JS and Ors v SSWP [2013] EWHC 3350

SG and Ors v SSWP [2014] EWCA Civ 156

SG and Ors v SSWP [2015] UKSC 16 
DA and Ors v SSWP [2017] EWHC 1446 (Admin)

DA and Ors v SSWP [2018] EWCA Civ 504

SC and Ors v SSWP [2018] EWHC 864 (Admin)

\section{Abbreviations}

CTC - Child Tax Credit

DWP - Department of Work and Pensions

ESA - Employment Support Allowance

EWHC - High Court

EWCA - Court of Appeal

FtT - First tier Tribunal

SSWP - Secretary of State for Work and Pensions

UKSC - Supreme Court

UT - Upper Tribunal

WCA - Work Capability Assessment

WRAG - Work Related Activity Group 